\title{
The Creative Reform and Practice of Studio Mode in Teaching Art Design-with Examples from Animation Design and Production Major of Hainan College of Software Technology
}

\author{
Yang Liu" a and Yingying Guo ${ }^{1, b^{*}}$ \\ ${ }^{1}$ Hainan College of Software Technology, 128 FuHai Road, Qionghai City, Hainan, China \\ a250095787@qq.com, ${ }^{b} 174707013 @ q q . c o m$ \\ *The corresponding author
}

\begin{abstract}
Keywords: Studio; Teaching mode; Creative reform; Practice; Animation design
\end{abstract}
\begin{abstract}
Studio" teaching mode has been widely used in teaching practical skills for design majors and has won fairly good results. It has effectively resolved the supply-demand relationship among schools, students and companies. Authors of this paper use example from animation design and production major of Hainan College of Software Technology to give a complete explanation of the application of creative reform and practice of studio teaching mode in vocational education.
\end{abstract}

\section{Introduction}

With the deepening of educational reform, constant teaching reforms have taken place in vocational education. What is worth special notice is that in 2016, Vocational Education Week has been held with the theme of "Carry Forward the Spirit of Craftsmanship to Create a Powerful Country". Thus, integrating teaching with production and cooperating with companies to produce qualified and professional graduates with skills in the corresponding industry have become the major goal for vocational education at present. Under this circumstance, vocational schools should advocate production-teaching talks with companies, and promote and introduce school-company cooperation examples to realize cooperation, coexistence and win-win development with companies.

Animation design and production is a new major which has come into being in recent years. It is a technology-based and art-assisted major. Due to its short history, insufficient teaching experience and backward teaching mode, its graduates have difficulties in meeting industry standards in the field of practical skills, which results a gap between the personnel produced and the personnel demanded. Therefore, it has become an urgent task to bridge the gap, meet the demand of industries, focus more on students' production capacity and improve their professional ability.

Studio teaching mode uses industry regulations as its standards, brings business projects into classroom practice and is focused on giving professional training to students, thus it can combine schools, students and companies together to ensure the development of practical skills and creativity in students and to bridge the gap between the graduates schools produce and the employees companies desire. Animation design and production is characterized with professional skills and strong practical ability. In view of this, the course design should focus on teaching skills and practice. Skill lessons should be used to explain theory and to supplement practice part while the practice lessons should mainly take the form of studio by setting up class modules and combining different modules together to form a complete project, thus, to integrate theory and practice and bring schools, students and companies together.

\section{The Creation and Advantage of Studio Teaching Mode}

It is conducive to the cultivation of talents in application with integrated theory and practice and finally to the promotion of all-round development of professional technical talents.

It is shown specifically as follows: under the guidance of professional teachers with "Dual 
Qualifications" who on one hand possess teaching and research capability and on the other hand have experiences of working in companies, studio teaching mode establishes basic courses and case studies which are related to the production of social practice projects according to teachers' expertise. It then sets up different sections according to the skills which should be mastered at different stages. Several specific learning tasks should also be included in each section. In this way, teaching purposes have been carried through different learning stages, the design of sections and the explanation of related learning tasks. At the same time, the working environment can be simulated while explaining learning tasks, so to combine school learning with real practice, reduce the gap between students' practical ability and that the industry desires and ultimately improve the overall level of schools and lay a good foundation for students' employment.

The creative reform of studio teaching mode is conducive to the extensive carrying out of school-company cooperation featuring the combination of working and school studying. Through studio mode, schools can have more contact with competitive enterprises in the industry and introduce business project cases into the classroom, so to integrate classroom teaching with enterprise practice, get rid of the obsolete teaching method of indoctrination and set up a new concept of cultivating new professional skilled talent.

The creative reform of studio teaching mode is conducive to the enhancing of teachers' professional skills and the improving of the overall level of teaching staff. Teachers are the main practitioners of vocational education. Studio teaching mode requires teachers to not only have teaching and research ability but also possess experiences of working in companies, so to have excellent professional and practical ability of the working positions their graduates intend to work for. At the same time, they should know industry regulations and procedures. Only in this way can they adapt themselves to the creative reform of studio teaching mode.

\section{The Studio Teaching Mode in Animation Design and Production Major in Hainan College of Software Technology}

Animation design and production major of Hainan College of Software Technology is a specialty major in Hainan. In recent years, investigation and research have been done in this field and have brought up teaching methods which are based on working processes and driven by projects. This kind of teaching method divides enterprise projects into modules and teaches them in classroom. It features school-company cooperation and the combination of working and school studying. It attempts to build up a studio teaching mode based on working positions and balance students employment and the demand of enterprises and companies, so to realize the win-win situation among students, enterprises and schools.

After several years' contemplation, Hainan College of Software Technology decided to implement "school-enterprise cooperation" mode in March, 2012 and started to have deep cooperation with Mudanjiang University Animation Company Limited; in January, 2014, it further proposed to carry out theoretical research and exploration of the "studio" teaching mode and began to practice this mode in September, 2015. Later, it formed Shihu Studio, Dashi Studio, Yuanse Studio, and Tumou Studio and so on.

The Establishment of Studio Mode Teaching Frame. Animation design and production takes cultivating professional technical talent who can meet the requirements of enterprises as its goal. Thus, instead of establishing classes, animation design and production major of Hainan College and Software Technolgoy has formed different studios according to the development trend of this major and enterprise standards, including Yuanse Studio based on painting, Dashi Studio based on creative design, Shihu Studio based on 3-D animation production and Tumou Studio based on games development. Among them, Yuanse Studio is responsible for the teaching of basic courses while Dashi Studio, Shihu Studio and Tumou Studio for theoretical courses and practical skills of different orientations under the same major. Different studios have different focuses according the requirements of working positions it intends for its graduates and the development needs of building Hainan into an "International Tourist Island". Among all the studios, Yuanse Studio focuses on the training of drawing, including sketch, coloring and quick sketch; Dashi Studio put more 
attention to animation design, including the design of roles, settings and props; Shihu Studio emphases on 3-D animation production, including the production of modes, rigging, the setting of lens and actions, texturing, rendering settings, post-production and special effects and so on; Tumou Studio works on games development, including the writing of stories, art design, plot design and so on. Yuanse Studio is mainly responsible for the teaching of the basic course in the first semester while Dashi Studio, Shihu Studio and Tumou Studio for the professional courses and internships in the remaining semesters.

The Enforcement of Studio Teaching. After adopting "Studio" teaching mode, studios have been classified into different types according to their nature, teaching groups have been formed and the number of students for each studio has been limited to 20 to enable effective teaching. At the same time, teachers are able to teach students in accordance of their aptitude after knowing their characteristics through observing them and talking to them in the very beginning of the teaching. Therefore, teaching quality has been enhanced with reduced lecturing time, increased exercise and specified student assistance. We've increased the proportion of student professional design production ability and their employment level when evaluating teachers' performance besides counting their normal working hours, to make student employment an important criteria in teachers performance assessment. Attention has also been paid to the balance of working and playing, quality development activities, the improvement of students' collective cohesion and team spirit and their overall development.

Along the way of developing studio teaching, we attach great attention to including local folktales, legends and religious beliefs in studio production practice to increase students' original creativity, to enable our teaching to form and keep a close relationship with research, and to take the road of letting originality and research play a complementary role and to combine production, learning and research to cultivate professional technological talents. In this way, studio teaching is oriented by employment, but at the same time is not controlled by commercial ideas.

\section{Achievements of Studio Teaching}

With the enforcement of studio teaching, a fundamental change has taken place in both the overall curriculum and specific courses because it advocates learning by stages, connects unrelated curriculum into different modules, and arrange them by learning order. Learning stages are connected to each other through virtual or real business cases with emphasis both to fundamentals and professional skills, and a deep understanding of how to make student learning systematic, professional and precise. Therefore, it creates favorable conditions for schools to produce graduates who have the ability to solve problems from different perspectives.

At the same time, teachers participating in studio teaching have shown great interest and enthusiasm in working, especially in taking professional development trainings and academic researches, and in instructing students and making production specifications and so on. On one hand, teachers started to contact training institutions or industry leading companies according their interested research field and to the actual needs of the studio to improve their professional production ability by the means of attending online courses or taking a position in companies for a period of time to know the latest specifications and developmental trend of this field. They have paid more attention to accumulating experiences and reflecting on teaching results. They are able to convert the experience they accumulated from the studio into academic researches. They have not only raised their theoretical research level, but the most important thing is that they are able to combine teaching, research and local culture together to facilitate the study of local cultures and the production of original animation.

\section{Conclusion}

The creation and practice of workshop teaching mode in animation design and production major of vocational schools has provided a feasible plan of cultivating professional technological talents who are able to meet social and enterprise needs. It is an effective method to achieve the 
government-advocated goal of developing advanced professionally skilled personnel. It takes project-driven approach based on work process as its major teaching method to enable students to know the latest industry trends and specifications, to master the currently popular production technologies and to cultivate their group pride and team spirit. It not only helps the employment, but more importantly it bridges the gap between qualities and skills of graduates demanded by companies and that schools cultivate. It is a win-win solution to schools, students and companies.

\section{References:}

[1] Cheng Jiang, Reform and Implementation of "Studio Project" Teaching Mode - Taking Guangzhou Academy of Fine Arts School of Industrial Design as an Example [J] Decoration, March 2013 Total No. 239;

[2] She Li and Long Yibiao, Art Design Studio Engineering Combined with Practical Training Teaching Mode - Discussions about Innovative Ideas and Teaching Mode Reform[J] Higher Education Forum, $7^{\text {th }}$ Volume of July 2011;

[3] Lin Fang, A Tentative Exploration of the Application of "Studio" Teaching Mode in Animation Design and Production Major in Vocational Schools [J], Education and Occupation, $11^{\text {th }}$ Volume of April 2010;

[4] Long Yibiao, Exploration and Research on the Application of Studio Teaching Mode in Art and Design Major in Vocational Schools [D], Guangxi Normal University, March 2012;

[5] Cha Xiaofei, Analysis of the Characteristics of Studio Teaching Mode in Vocational Schools in Jiangsu Province. [D], Nanjing Arts Institute, May 2012;

[6] Liu Yang, Fu Yingbin, Guo Yingying, Exploration of Workshop Teaching Mode in Animation Major in Vocational Schools [J], Art and Science, November 2014;

[7] Liu Yang, Exploration and Practice of New Studio Teaching Mode in Animation Major-Taking Hainan College and Software Technology As an Example[J], Contemporary Education Practice and Teaching Research, October 2015.

[8] Zhou Libo, The platform of combination of work and study -- Discussion on teaching practice of art design studio Art Education Research[J],March 2013.

[9] Jia Jia, Study on the talent training mode of Higher Vocational Art Design Speciality "studio"[J], Beauty and the times (City Edition), August 2015.

[10] Qin Weiyun, Research on the operation of art design studio in Higher Vocational Colleges[D], Hunan Normal University, December 2014. 